\title{
Prediction of wear loss quantities of ferro-alloy coating using different machine learning algorithms
}

\author{
Osman ALTAY ${ }^{1}$, Turan GURGENC ${ }^{2, *}$, Mustafa ULAS ${ }^{1}$, Cihan ÖZEL $^{3}$ \\ ${ }^{1}$ Software Engineering, Firat University, Elazig 23119, Turkey \\ ${ }^{2}$ Automotive Engineering, Firat University, Elazig 23119, Turkey \\ ${ }^{3}$ Mechanical Engineering, Firat University, Elazig 23119, Turkey \\ Received: 23 May 2018 / Revised: 20 July 2018 / Accepted: 22 September 2018 \\ C The author(s) 2018. This article is published with open access at Springerlink.com
}

\begin{abstract}
In this study, experimental wear losses under different loads and sliding distances of AISI 1020 steel surfaces coated with (wt.\%) $50 \mathrm{FeCrC}-20 \mathrm{FeW}-30 \mathrm{FeB}$ and $70 \mathrm{FeCrC}-30 \mathrm{FeB}$ powder mixtures by plasma transfer arc welding were determined. The dataset comprised 99 different wear amount measurements obtained experimentally in the laboratory. The linear regression (LR), support vector machine (SVM), and Gaussian process regression (GPR) algorithms are used for predicting wear quantities. A success rate of 0.93 was obtained from the LR algorithm and 0.96 from the SVM and GPR algorithms.
\end{abstract}

Keywords: surface coating; plasma transfer arc (PTA) welding; wear; prediction; machine learning algorithms

\section{Introduction}

Wear and friction cause significant economic losses in mechanically driven machine parts [1]. For this reason, there is a strong demand for materials that increase the service life of engineering machines and parts by reducing wear. The surface coating process is one of the effective methods used to improve the wear resistance performance of softer and tough-substrate material surfaces [2]. Wear-resistant surfaces are important applications in prolonging the life of machine parts in mechanical contact with each other. Resistance to wear can be increased by depositing hard coatings such as carbide, nitride, or boride on the surfaces of metallic machine parts [3].

For coating surfaces by melting and depositing, different welding methods are used, such as metal inert gas welding, metal active gas welding, plasma transferred arc welding (PTAW) [4], gas tungsten arc welding, submerged arc welding, and flux cored arc welding [5]. The PTAW method has a number of advantages compared to other conventional welding techniques, such as a high deposition rate, lower heat input, excellent arc stability [6], intensive energy density, high welding speeds, and low thermal distortion of the parts [7].

Because of their economic properties, iron-based alloys are melted and deposited on the surfaces and wear-resistant coating layers are formed. The $\mathrm{FeCrC}$ alloys with high $\mathrm{Cr}$ and $\mathrm{C}$ contents are typically preferred because of the formation of hard carbides such as $\mathrm{M}_{7} \mathrm{C}_{3}$ and $\mathrm{M}_{23} \mathrm{C}_{6}$ in surface coating applications [8]. When the strong carbide forming elements, such as $\mathrm{Nb}, \mathrm{V}, \mathrm{W}$, and $\mathrm{Ti}$ together with $\mathrm{FeCrC}$ alloys are melted together, the hardness of the carbides formed increases and fine-grained carbides such as MC are formed [9]. Another method of increasing wear resistance of the surfaces is boriding; however, the process is extremely slow when a conventional thermochemical process is used. Therefore, to obtain hard borides on the surfaces, pure boron and FeB powders are melted and deposited on substrate surfaces with welding [10].

Numerous studies are required to determine the wear

* Corresponding author: Turan GURGENC, E-mail: tgurgenc@firat.edu.tr 
resistance of abrasion-resistant tribological materials to be used under different operating conditions, and these experiments could be time-consuming [11]. Thus, in order to reduce the number of experiments and reduce the cost of experimental studies, there has been an increasing need to develop machine learning algorithms, which in recent years have been able to make use of experimental data to predict wear behaviors of materials [12].

Machine learning algorithms have been previously used for wear loss testing in different studies. In the study conducted by Batista et al., wear resistance was predicted by using the linear regression (LR) algorithm [13]. In another study, the thickness of the abrasion resistant hard chrome layer was predicted using the support vector regression (SVM) algorithm [14]. Tool wear was predicted using the Gaussian mixture regression model in Ref. [15]. Artificial neural networks (ANN) are among the most commonly used methods for predicting wear loss [16]. A further study predicted wear loss using the ANN algorithm [17]. Tan et al. used SVM and ANN algorithms to predict wear loss and friction coefficients [18].

In this study, different machine learning methods were used to predict wear losses of low carbon steel surface alloyed by the PTAW method using Fe-CrW-B-C and Fe-Cr-B-C elements. The SVM and Gaussian process regression (GPR) algorithms were applied, as well as the LR algorithm that is frequently used for the prediction of quantitative values. In this study, the interaction LR, which is a different version of the LR algorithm, the kernel function cubic in the SVM method, and the rational quadratic in the GPR method are used.

\section{Data acquisition}

In our study, the experimental wear characteristics of 11 coated specimens, whose microstructure and mechanical properties were determined in previous studies, were utilized and machine learning algorithms were developed to estimate the wear amounts [19, 20]. Coating operations were performed, according to the parameters presented in Table 1, by the PTAW method and AISI 1020 steel was used as the substrate material. The hardness of the coating layers was measured by applying a $200 \mathrm{~g}$ mass from the midpoint of the top surface of the coating to the primary material at $0.25 \mathrm{~mm}$ intervals with a microhardness test device. The average microhardness values of the samples are presented in Table 2. Wear tests were conducted in a "block-on-disc" adhesive wear tester at normal loads of $19.62 \mathrm{~N}, 39.24 \mathrm{~N}$, and $58.86 \mathrm{~N}$. The abrasive was 15-mm-diameter AISI 52100 bearing steel and the samples were worn at a total of $900 \mathrm{~m}$ sliding distance for each load. Weight losses were measured with a precision scale with a $10^{-5} \mathrm{~g}$ accuracy after every $300 \mathrm{~m}$. The wear losses of the specimens at $19.62 \mathrm{~N}, 39.24 \mathrm{~N}$, and $58.86 \mathrm{~N}$ loads are shown in Figs. 1-3.

In order to be able to train the machine learning algorithms, powder compositions, average microhardness of the coating layers $\left(\mathrm{HV}_{\mathrm{av}}\right)$, applied load, and sliding distance are given as input parameters. Experimental wear loss results obtained in the laboratory

Table 1 PTAW production parameters.

\begin{tabular}{|c|c|c|c|c|c|c|c|c|c|c|c|}
\hline Sample & S1 & $\mathrm{S} 2$ & S3 & S4 & S5 & S6 & S7 & S8 & S9 & $\mathrm{S} 10$ & S11 \\
\hline Current (A) & 140 & 160 & 120 & 140 & 160 & 120 & 140 & 160 & 120 & 140 & 160 \\
\hline Coating speed $(\mathrm{m} / \mathrm{min})$ & 0.15 & 0.15 & 0.1 & 0.1 & 0.1 & 0.15 & 0.15 & 0.15 & 0.1 & 0.1 & 0.1 \\
\hline Coating powder composition (wt.\%) & \multicolumn{5}{|c|}{$50 \mathrm{FeCrC}-20 \mathrm{FeW}-30 \mathrm{FeB}$} & \multicolumn{6}{|c|}{$70 \mathrm{FeCrC}-30 \mathrm{FeB}$} \\
\hline Voltage (V) & \multicolumn{11}{|c|}{$19-20$} \\
\hline Plasma gas (Argon) flow rate $(\mathrm{L} / \mathrm{min})$ & \multicolumn{11}{|c|}{0.5} \\
\hline Shielding gas (Argon) flow rate (L/min) & \multicolumn{11}{|c|}{8} \\
\hline
\end{tabular}

Table 2 Average microhardness values of coating layers.

\begin{tabular}{cccccccccccc}
\hline Sample & S1 & S2 & S3 & S4 & S5 & S6 & S7 & S8 & S9 & S10 & S11 \\
\hline $\mathrm{HV}_{(\text {av }}$ & 1217 & 1030 & 995 & 795 & 725 & 1096 & 991 & 858 & 812 & 703 & 621 \\
\hline
\end{tabular}

$\mathrm{HV}_{(\mathrm{av})}$ : Average microhardness of coating layer 


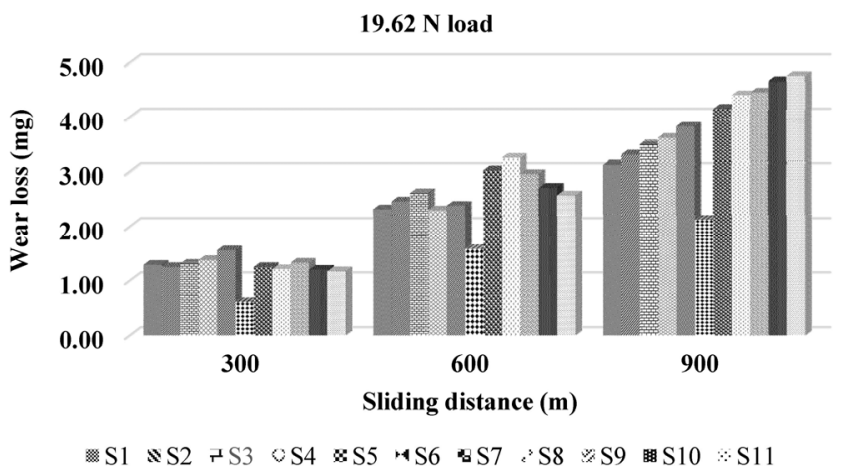

Fig. 1 Wear loss according to sliding distance at $19.62 \mathrm{~N}$.

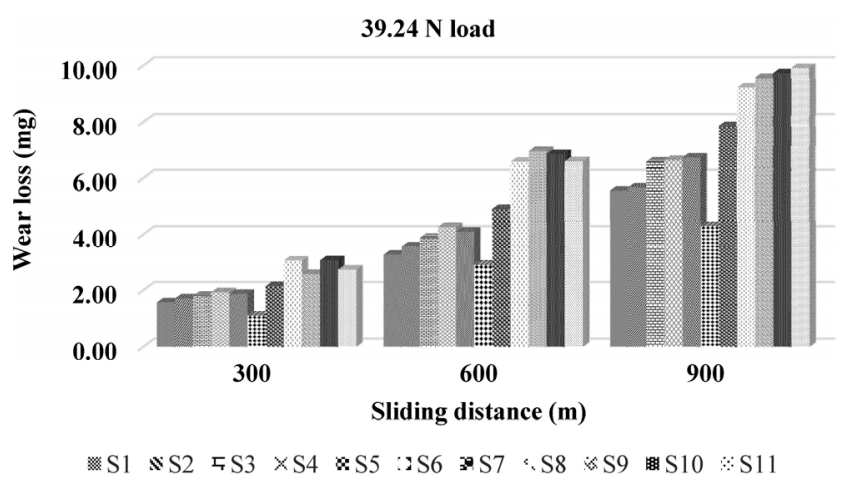

Fig. 2 Wear loss according to sliding distance at $39.24 \mathrm{~N}$.

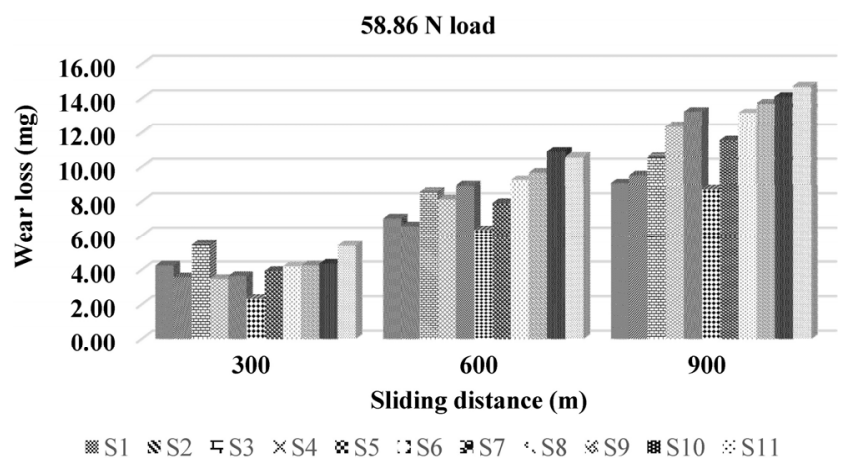

Fig. 3 Wear loss according to sliding distance at $58.86 \mathrm{~N}$.

are taken as output parameters. The aim of the model is to predict the wear losses depending on the input parameters (powder compositions, average microhardness of the coating layers $\left(\mathrm{HV}_{\mathrm{av}}\right)$, applied load and sliding distance).

\section{Machine learning algorithms}

\subsection{Linear regression}

Regression analysis involves an answer variable $y$ and a single predictor variable $x$. This is the simplest form of regression and is used as the linear function of $y, x$, and is expressed as follows [21]:

$$
y=b+w x
$$

It is assumed that the variance of $y$ is constant and that $b$ and $w$ are the regression coefficients that determine the $y$-intersection and slope, respectively. Therefore, the regression coefficients $w$ and $b$ can be considered as weights, as follows [21]:

$$
y=w_{0}+w_{1} x
$$

These coefficients can be solved by the least squares method, which estimates the most suitable straight line that minimizes the error between the actual data and the estimate of the line. Variable $D$ is the set of values for some populations, $x$ is the response variable, and $y$ is the set of values associated with the response variable $x$. The training set includes the data points of the form $\left(x_{1}, y_{1}\right),\left(x_{2}, y_{2}\right), \ldots,\left(x_{\mathrm{D}}, y_{\mathrm{D}}\right), D$. Regression coefficients can be estimated using Eqs. (3) and (4) [21].

$$
\begin{gathered}
w_{1}=\frac{\sum_{i=1}^{D}\left(x_{i}-\bar{x}\right)\left(y_{i}-\bar{y}\right)}{\sum_{i=1}^{D}\left(x_{i}-\bar{x}\right)^{2}} \\
w_{0}=\bar{y}-w_{1} \bar{x}
\end{gathered}
$$

where $\bar{x}$ is the average of $x_{1}, x_{2}, \ldots, x_{D}$, and $\bar{y}$ is the average of $y_{1}, y_{2}, \ldots, y_{D}$. The $w_{0}$ and $w_{1}$ coefficients typically provide good approximations to complex regression equations. In this study, we used the interaction LR.

\subsection{Support vector machine}

The SVM was presented in 1995 as a machine learning algorithm by Cortes and Vapnik to achieve a solution for regression and classification problems [22]. The SVM algorithm has numerous variations according to the kernel function used. There is no precise information regarding which core function will yield better results [23].

In the SVM algorithm $X=\left\{x_{1}, x_{2}, \ldots, x_{n}\right\}$ is the input variable, $T=\left\{t_{1}, t_{2}, \ldots, t_{n}\right\}$ is the target vector, and $Y=\left\{y_{1}, y_{2}, \ldots, y_{n}\right\}$ is the SVM result vector. Equation (5) represents a linear regression model that establishes a relationship between input and output values. In Eq. (5), $x_{i}$ is the input sample and $y_{i}$ is the output 
sample, $w$ is the weight, and $b$ is the bias value [24].

$$
y_{i}=w_{i}^{T} x_{i}+b
$$

In this study, a quadratic function is used as the kernel function in the SVM algorithm. The quadratic function is as follows [24]:

$$
L_{\text {quad }}(f(x)-y)=(f(x)-y)^{2}
$$

The solution is given by the following equation, which is the resultant of the optimization problems. This equation is simplified by using the Karush-KuhnTucker conditions, which are given in Eqs. (7) and (8) [24].

$$
\begin{gathered}
\min _{\beta} \frac{1}{2} \sum_{i=1}^{l} \sum_{j=1}^{l} \beta_{i} \beta_{j}\left\langle x_{i}, x_{j}\right\rangle-\sum_{i=1}^{l} \beta_{i} y_{i}+\frac{1}{2 C} \sum_{i=1}^{l} \beta_{i}^{2} \\
\bar{\alpha}_{i} \bar{\alpha}_{i}^{*}=0, i=1, \ldots, l
\end{gathered}
$$

with constraints [24]:

$$
\sum_{i=1}^{l} \beta_{i}=0
$$

The Cubic kernel function is as follows [24]:

$$
K\left(x, x^{\prime}\right)=1+\left(x, x^{\prime}\right)+\frac{1}{2}\left(x, x^{\prime}\right) \min \left(x, x^{\prime}\right)-\frac{1}{6} \min \left(x, x^{\prime}\right)^{3}
$$

The regression function is as follows [24]:

$$
w=\sum_{i=1}^{l} \beta_{i} x_{i} \text { and } b=-\frac{1}{2}\left\langle w,\left(x_{r}+x_{s}\right)\right\rangle
$$

\subsection{Gaussian process regression}

The GPR is a set of infinitely random variants in which any finite subset has a common Gaussian distribution. The Gaussian multivariate distribution can be explained as a natural extension of functions, that is, the mean vector is infinitely long and the covariance matrix has infinite size [25].

The vector $x_{n}$ indicates a specific position in the input field, and $x_{N} \equiv\left\{x^{n}\right\}_{n=1}^{N}$ corresponds to the set of training input vectors $y_{N} \equiv\left\{y^{n}\right\}_{n=1}^{N}$ target vectors. The GPR $f(x)$ can be precisely defined by the mean and covariance (or kernel) functions. These functions are specified individually and comprise a set of parameters, the so-called hyperparameter, as well as a specification of a functional form. Before the training data is evaluated, the average function is used to define the expected value of the function at any point in the input field. The average function is as follows $[25,26]$ :

$$
k\left(x, x^{\prime}\right)=E(f(x))
$$

The idea of similarity between data points is essential for audited learning. This is a basic similarity hypothesis that could have an essentially similar target value, with the nearest entries $x$, so that training points close to another point can be informative about that estimate of that point. In the GPR parity, the covariance function defines closeness or similarity. The covariance function for the two functional values evaluated at $x$ and $x$ set points is as follows $[25,26]$ :

$$
k\left(x, x^{\prime}\right)=E\left[(f(x)-m(x))\left(f\left(x^{\prime}\right)-m\left(x^{\prime}\right)\right)\right]
$$

The knowledge of this covariance function makes it possible to obtain a function value when the knowledge of the other is taken into consideration. Therefore, in the covariance function $k\left(x, x^{\prime}\right), x$ and $x^{\prime}$ can be interpreted as the measure of the distance between input points. The Gaussian process can be written as follows [25, 26]:

$$
f(x) \sim G P\left[m(x), k\left(x, x^{\prime}\right)\right]
$$

The basic GPR comprises a simple zero mean and quadratic exponent synonym functions. The zero mean function for all $x$ values is as follows [26]:

$$
m(x)=0
$$

In this study, we used the rational quadratic covariance function for the kernel function. The rational quadratic kernel function equation is as follows [27]:

$$
k_{\mathrm{RQ}}\left(x, x^{\prime}\right)=\sigma_{f}^{2}\left(1+\frac{1}{2 \propto} r^{2}\right)^{-\infty}
$$

\section{Results and discussion}

In this study, we proposed to determine the wear loss of AISI 1020 surfaces alloyed by the PTAW method, 
and LR, SVM, and GPR were used as the machine learning methods to design the model. Four different values were taken as input parameters. While the interaction function is used in the LR algorithm, the cubic function is used in the kernel function in the SVM algorithm, and the rational quadratic function is used in the GPR algorithm. Cross-validation was used during testing of the constructed model. This method is taken as $k$-value 5 and all data is provided as test and training data for the $k$-fold cross-validation [25]. Three different evaluation criteria were applied. The applied criteria are RMSE (Eq. (17)), R-squared (Eq. (18)), and MAE (Eq. (19)) [25].

$$
\begin{gathered}
\mathrm{RMSE}=\sqrt{\left(\frac{1}{p}\right) \times \sum_{j}\left|t_{j}-\theta_{j}\right|^{2}} \\
R^{2}=1-\left(\frac{\sum_{j}\left(t_{j}-o_{j}\right)^{2}}{\sum_{j}\left(o_{j}\right)^{2}}\right) \\
\mathrm{MAE}=\frac{1}{N} \sum_{i=1}^{N}\left|y_{i}-\bar{f}_{i}\right|
\end{gathered}
$$

It was observed that the rational quadratic GPR method yielded more efficient results in the RMSE, R-squared, and MAE results. The quadratic rational GPR method yielded the best result in the two evaluation criteria. An R-squared value of 0.96 was achieved in the cubic SVM and rational quadratic methods, while a success rate of 0.93 was obtained in the interaction LR method. The determined values are presented in Table 3. All the MATLAB scripts of the related algorithms in the study were self-coded, and the MATLAB platform was licensed by the Firat University.

The observed and predicted values of the proposed model are shown in Fig. 4. As can be seen, the values predicted by the model proposed in the study are in good agreement with the experimental. The LR, SVM, and GPR results are compared in Fig. 5.

Using the proposed model in the manufacturing industry for the production of surface-coated wearresistant parts will result in numerous advantages. Among these advantages are critical aspects such as reducing required manpower, reducing production costs, and preventing time lost conducting experiments. The proposed model is expected to be used specifically in the production process of parts that are subjected to high wear and used in the rolling industry, agricultural machinery, and mining industry, such as milling and crushing.

Table 3 Performance of methods for predicting wear losses.

\begin{tabular}{cccc}
\hline & $\begin{array}{c}\text { Linear regression } \\
\text { (interaction } \\
\text { linear) }\end{array}$ & $\begin{array}{c}\text { SVM } \\
\text { (cubic SVM) }\end{array}$ & $\begin{array}{c}\text { Rational } \\
\text { quadratic } \\
\text { GPR }\end{array}$ \\
\hline RMSE & 0.86 & 0.70 & 0.69 \\
R-Squared & 0.93 & 0.96 & 0.96 \\
MAE & 0.69 & 0.55 & 0.52 \\
\hline
\end{tabular}
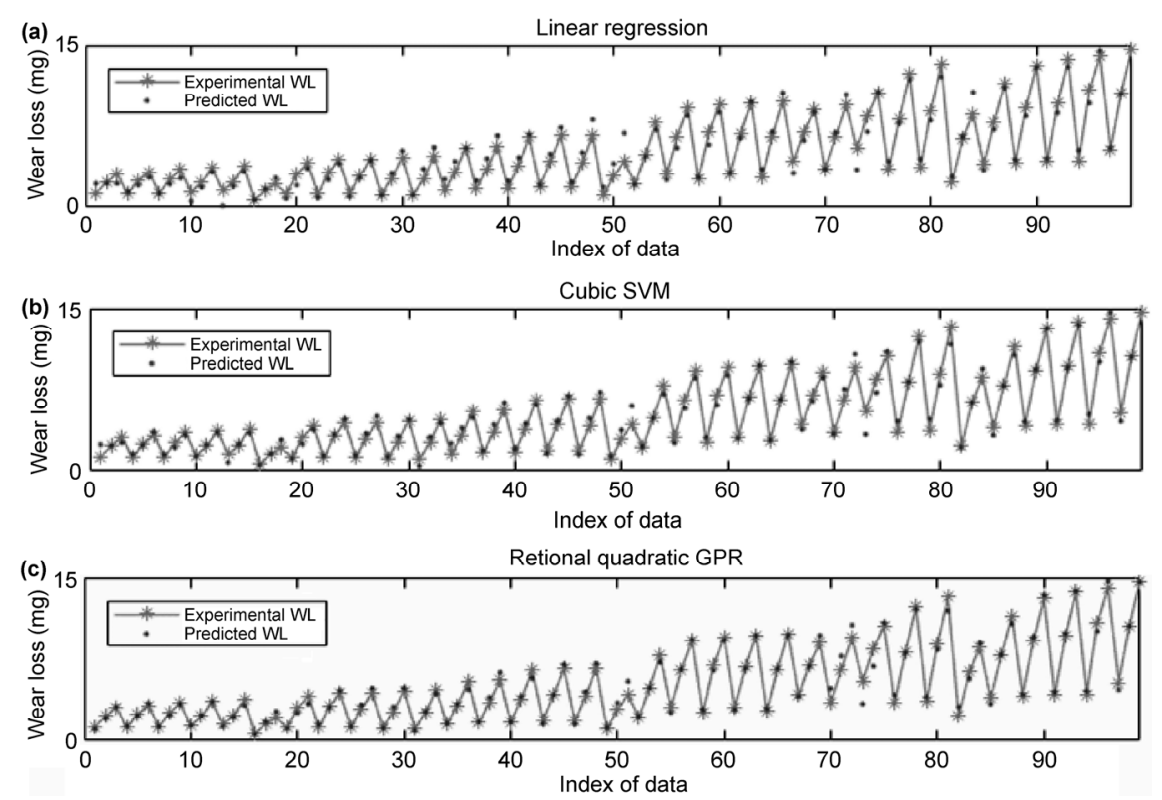

Fig. 4 Experimental and predicted wear losses: (a) LR results, (b) Cubic SVM results, and (c) rational quadratic GPR results. 

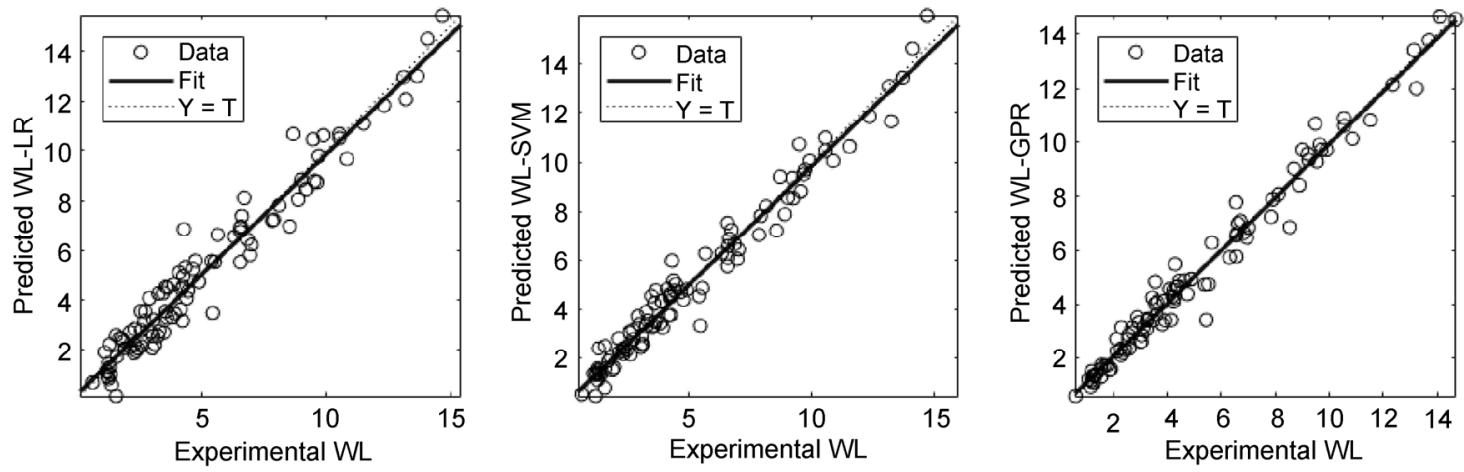

Fig. 5 Regression analysis graphs.

\section{Conclusions}

The wear amounts of the surface coatings $\mathrm{FeCrC}$, $\mathrm{FeW}$, and FeB ferro-alloys, were predicted by using machine learning algorithms. It was observed that the wear amount could be predicted by the proposed model by using the machine learning algorithms. With the proposed model, time loss, production costs, and man-hours could be saved.

The LR, SVM, and GPR algorithms were used in the machine learning to predict the amount of wear. The success rate of the LR algorithm was the lowest, while the success rates of the SVM and GPR algorithms were similar; R-squared was calculated as 0.93 in the LR algorithm, and 0.96 in the SVM and GPR algorithms. Although the R-squared values were the same, the GPR algorithm yielded better results with little difference in the RMSE and MAE values. It was observed that a more efficient model could be created by using the GPR algorithm, which yielded the best results among the proposed machine learning algorithms when the amount of wear was predicted.

\section{Acknowledgments}

All the Matlab scripts of related algorithms in the article are coded ourselves. The used Matlab platform is licensed by Firat University.

Open Access: The articles published in this journal are distributed under the terms of the Creative Commons Attribution 4.0 International License (http:// creativecommons.org/licenses/by/4.0/), which permits unrestricted use, distribution, and reproduction in any medium, provided you give appropriate credit to the original author(s) and the source, provide a link to the Creative Commons license, and indicate if changes were made.

\section{References}

[1] Amann T, Gatti F, Oberle N, Kailer A, Rühe J. Galvanic ally induced potentials to enable minimal tribochemical wear of stainless steel lubricated with sodium chloride and ionic liquid aqueous solution. Friction 6(2): 230-242 (2018)

[2] Liu J, Yang S, Xia W, Jiang X, Gui C. Microstructure and wear resistance performance of $\mathrm{Cu}-\mathrm{Ni}-\mathrm{Mn}$ alloy based hardfacing coatings reinforced by WC particles. Journal of Alloys and Compounds 654: 63-70 (2016)

[3] Kommer M, Sube T, Richter A, Fenker M, Schulz W, Hader B, Albrecht J. Enhanced wear resistance of molybdenum nitride coatings deposited by high power impulse magnetron sputtering by using micropatterned surfaces. Surface and Coatings Technology 333: 1-12 (2018)

[4] Olivares E A G, Díaz V M V. Study of the hot-wire TIG process with AISI-316L filler material, analysing the effect of magnetic arc blow on the dilution of the weld bead. Welding International 32(2): 139-148 (2018)

[5] Zahiri R, Sundaramoorthy R, Lysz P, and Subramanian C. Hardfacing using ferro-alloy powder mixtures by submerged arc welding. Surface and Coatings Technology 260: 220-229 (2014)

[6] Motallebzadeh A, Atar E, Cimenoglu H. Microstructure and tribological properties of PTA deposited Stellite 12 coating on steel substrate. Manufacturing Science and Technology 3: 224-228 (2015)

[7] Huang H, Han G, Qian Z, Liu Z. Characterizing the magnetic memory signals on the surface of plasma transferred arc cladding coating under fatigue loads. Journal of Magnetism 
and Magnetic Materials 443: 281-286 (2017)

[8] Wang X, Han F, Liu X, Qu S, Zou Z. Effect of molybdenum on the microstructure and wear resistance of Fe-based hardfacing coatings. Materials Science and Engineering: A 489(1-2): 193-200 (2008)

[9] Correa E, Alcântara N, Valeriano L, Barbedo N, Chaves R. The effect of microstructure on abrasive wear of a $\mathrm{Fe}-\mathrm{Cr}-$ $\mathrm{C}-\mathrm{Nb}$ hardfacing alloy deposited by the open arc welding process. Surface and Coatings Technology 276: 479-484 (2015)

[10] Eroglu M. Boride coatings on steel using shielded metal arc welding electrode: Microstructure and hardness. Surface and Coatings Technology 203(16): 2229-2235 (2009)

[11] Gao X, Dai K, Wang Z, Wang T, He J. Establishing quantitative structure tribo-ability relationship model using Bayesian regularization neural network. Friction 4(2): 105-115 (2016)

[12] Palavar O, Özyürek D, Kalyon A. Artificial neural network prediction of aging effects on the wear behavior of IN706 superalloy. Materials \& Design 82: 164-172 (2015)

[13] Batista J C A, Godoy C, Matthews A. Micro-scale abrasive wear testing of duplex and non-duplex (single-layered) PVD (Ti, Al) N, TiN and $\mathrm{Cr}-\mathrm{N}$ coatings. Tribology International 35(6): 363-372 (2002)

[14] Lasheras F S, Nieto P G, de Cos Juez F J, Vilán J V. Evolutionary support vector regression algorithm applied to the prediction of the thickness of the chromium layer in a hard chromium plating process. Applied Mathematics and Computation 227: 164-170 (2014)

[15] Wang G, Qian L, Guo Z. Continuous tool wear prediction based on Gaussian mixture regression model. The International Journal of Advanced Manufacturing Technology 66(9-12): 1921-1929 (2013)

[16] Xu L J, Xing J D, Wei S Z, Zhang Y Z, Long R. Artificial neural network prediction on wear properties of high vanadium high speed steel (HVHSS) rolls. Materials Science and
Technology 23(3): 315-319 (2007)

[17] Cetinel H, Öztürk H, Celik E, Karlık B. Artificial neural network-based prediction technique for wear loss quantities in Mo coatings. Wear 261(10): 1064-1068 (2006)

[18] Tan Y F, Long H, Wang X L, Xiang H, Wang W G. Tribological properties and wear prediction model of TiC particles reinforced Ni-base alloy composite coatings. Transactions of Nonferrous Metals Society of China 24(8): 2566-2573 (2014)

[19] Gurgenc T, Ozel C. Effect of Heat Input on Microstructure, Friction and Wear Properties of Fe-Cr-B-C Coating on AISI 1020 Surface Coated by PTA Method. Firat University Turkish Journal of Science \& Technology 12(2): 43-52 (2017)

[20] Ozel C, Gurgenc T. Effect of heat input on microstructure, wear and friction behavior of (wt.-\%) 50FeCrC-20FeW-30FeB coating on AISI 1020 produced by using PTA welding. PloS one 13(1): e0190243 (2018)

[21] Han J, Pei J, Kamber M. Data mining: concepts and techniques. Elsevier (2011)

[22] Cortes C, Vapnik V. Support-vector networks. Machine Learning 20(3): 273-297 (1995)

[23] Brereton R G, Lloyd G R. Support vector machines for classification and regression. Analyst 135(2): 230-267 (2010)

[24] Gunnb S R. Support vector machines for classification and regression. ISIS Technical Report 14(1): 5-16 (1998)

[25] Kong D, Chen Y, Li N. Gaussian process regression for tool wear prediction. Mechanical Systems and Signal Processing 104: 556-574 (2018)

[26] Aye S, Heyns P. An integrated Gaussian process regression for prediction of remaining useful life of slow speed bearings based on acoustic emission. Mechanical Systems and Signal Processing 84: 485-498 (2017)

[27] Roberts S, Osborne M, Ebden M, Reece S, Gibson N, Aigrain S. Gaussian processes for time-series modelling. Phil Trans $R$ Soc A 371(1984): 20110550 (2013)

Engineering at Firat University. He is a research assistant at the Department of Software Engineering, Manisa Celal Bayar University, Turkey. His research interests include data mining, bioinformatics, machine learning, and data science. 


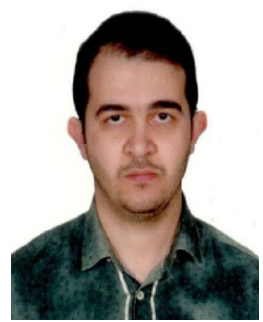

Turan GURGENC. He received his Ph.D. degree in Mechanical Engineering Department of Firat University in 2017 . He is a research

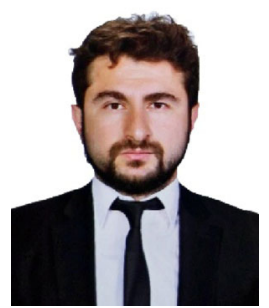

Mustafa ULAS. He is an assistant professor in Department of the Software Engineering. He has received BS degree in 2003 then he received the Ph.D. degree in Electric and Electronics Engineering Department of Firat University. Between the years 2004-2012, he worked as lecturer in the

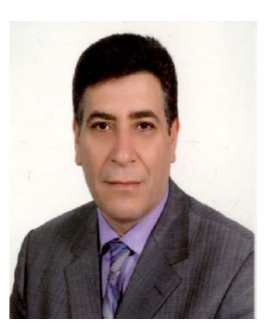

Cihan ÖZEL. He received his Ph.D degree in Mechanical Engineering Department of Firat University in 2000. He is currently an associate assistant in Automotive Engineering Department, Firat University, Turkey. His research interests include surface coating, wear analysis, sintering, manufacturing and computational intelligence.

Department of Informatics, at the same time he was a software developer and was the manager of R\&D Department. He was vice president of Computer Center and Department of Informatics in 2008-2012. He worked for the University of Michigan in the USA as visitor researcher in 2013. His research interests include data mining, machine learning algorithms, big data and augmented reality.

professor in Mechanical Engineering Department, Firat University, Turkey. His research interests cover CNC machining, surface coating, wear and manufacturing. 